\title{
Argentina: TurbulenCia eCONÓMicA, POlARizACión SOCIAL Y REALINEAMIENTO POLÍTICO
}

\author{
Argentina: Economic Turbulence, Social Polarization and Political \\ Realignment
}

\section{MIGUEL DE LUCA}

Universidad de Buenos Aires-CONICET

\author{
ANDRÉS MALAMUD \\ Universidad de Lisboa, Instituto de Ciencias Sociales
}

\section{RESUMEN}

El resultado de las elecciones parlamentarias de 2009 abrió un panorama complejo y difícil para la presidenta Cristina Fernández de Kirchner. Al obtener un tercio de los votos emitidos, perdió el control de la Cámara de Diputados por decisión de los electores y, más tarde, el del Senado por divisiones en su propia coalición. La crispación social generada por el gobierno contribuyó a aglutinar a la oposición, previamente fragmentada, en dos alianzas electorales cuyo arraigo territorial complementario les permitió vencer al oficialismo en los principales distritos. La economía se resintió por la crisis global y por los desmanejos locales; aunque el colapso se evitó, la fragilidad fiscal persiste por la dificultad del gobierno para obtener financiamiento. Con minoría en el Congreso, una sociedad polarizada y la economía en la cuerda floja, la presidenta enfrenta sus últimos dos años sin vocación para la negociación política y sin perspectivas creíbles de reelección.

Palabras clave: Argentina, Elecciones 2009, realineamiento político, peronismo, Kirchner.

\begin{abstract}
The 2009 mid-term elections produced a complex scenario for President Cristina Fernández de Kirchner. By winning just one third of the vote, she lost the majority in the House and the Senatein the latter case due to divisions in the ruling coalition rather than because of the electoral results. Social distress nurtured by government behavior contributed to galvanizing a previously fragmented opposition. Hence, two electoral coalitions with non-rival territorial strongholds managed to defeat the incumbent party in the main districts. The economy resented both the global crisis and domestic mismanagement; although a meltdown was avoided, fiscal frailty persists due to a lack of alternative credit sources. Confronted with divided government, high social polarization and a stumbling economy, the President faces her next two years without visible inclination towards political accommodation or credible prospects of reelection.
\end{abstract}

Key words: Argentina, 2009 elections, political realignment, Peronism, Kirchner. 


\section{ARGENTINA 2009: UN PANORAMA COMPLICADO PARA LOS KIRCHNER}

¿Por qué la política argentina no se estabiliza como la brasileña, chilena o uruguaya? Esta pregunta desvela desde hace tiempo a académicos y analistas políticos, que sin embargo reconocen la diferencia entre Argentina y sistemas políticos fuera de equilibrio como el boliviano o el venezolano. Dado que se trata de una sociedad sin conflictos étnicos, con una economía relativamente diversificada, instituciones políticas "normales" y un contexto internacional favorable, la anomalía argentina no puede explicarse por referencia a factores estructurales sino a la acción humana. El año 2009 ha sido, en este sentido, revelador: los tres procesos que dan título a este artículo fueron causados por la estrategia, visiblemente contraproducente, del gobierno de Cristina Fernández de Kirchner (CFK), así como por la reacción imprevista de la sociedad civil y la oposición partidaria.

\section{a) Coyuntura social}

En 2008 Argentina vivió un nivel de polarización social que no experimentaba desde la década del primer peronismo (1946-1955). A partir del conflicto desatado entre el gobierno y el sector agropecuario por la decisión de elevar los impuestos a las exportaciones rurales ("retenciones"), la división entre kirchneristas y no kirchneristas -o entre los "K" y los "no K"- se capilarizó tanto que incluso las relaciones familiares se tensaron hasta un punto difícil de captar con herramientas cuantitativas. Durante los primeros meses de 2009, sin embargo, el enfrentamiento social se redujo apreciablemente, pero la crispación política permaneció latente y se expresó en elecciones que dejaron a CFK en minoría parlamentaria, escenario inédito para una administración con el sello del Partido Justicialista (PJ). Los cortes de rutas y las movilizaciones a favor y en contra del gobierno se redujeron significativamente hasta septiembre, cuando volvieron a dispararse. Los protagonistas de este tipo de protesta fueron el sindicato de camioneros, liderado por el secretario general de la Confederación General de Trabajadores (CGT) y aliado kirchnerista Hugo Moyano, y diversos grupos piqueteros, la mayoría de ellos alineados con el oficialismo. En octubre la participación piquetera en los cortes de ruta alcanzó al $60 \%$ del total; los sindicatos, en cambio, contribuyeron con apenas el 16\% (Ichaso 2009, ver Gráfico 1). Significativamente, la mitad de los cortes se llevó a cabo en la Ciudad Autónoma de Buenos Aires (CABA) y un cuarto en la circundante Provincia de Buenos Aires (PBA), manifestando el nivel de centralización de la política nacional y, al mismo tiempo, otorgando a este fenómeno mayor visibilidad mediática de lo que su difusión territorial justifica.

\section{b) Coyuntura económica}

La crisis financiera global de 2008 amenazó con acabar con el período de altas tasas de crecimiento económico registrado por la mayoría de los países sudamericanos. Sin embargo, mientras a fines de 2009 los mercados emergentes de la región estaban otra 
Gráfico 1: Porcentajes de los cortes de ruta y vía pública realizados por piqueteros en el último año (noviembre 2008-octubre 2009)

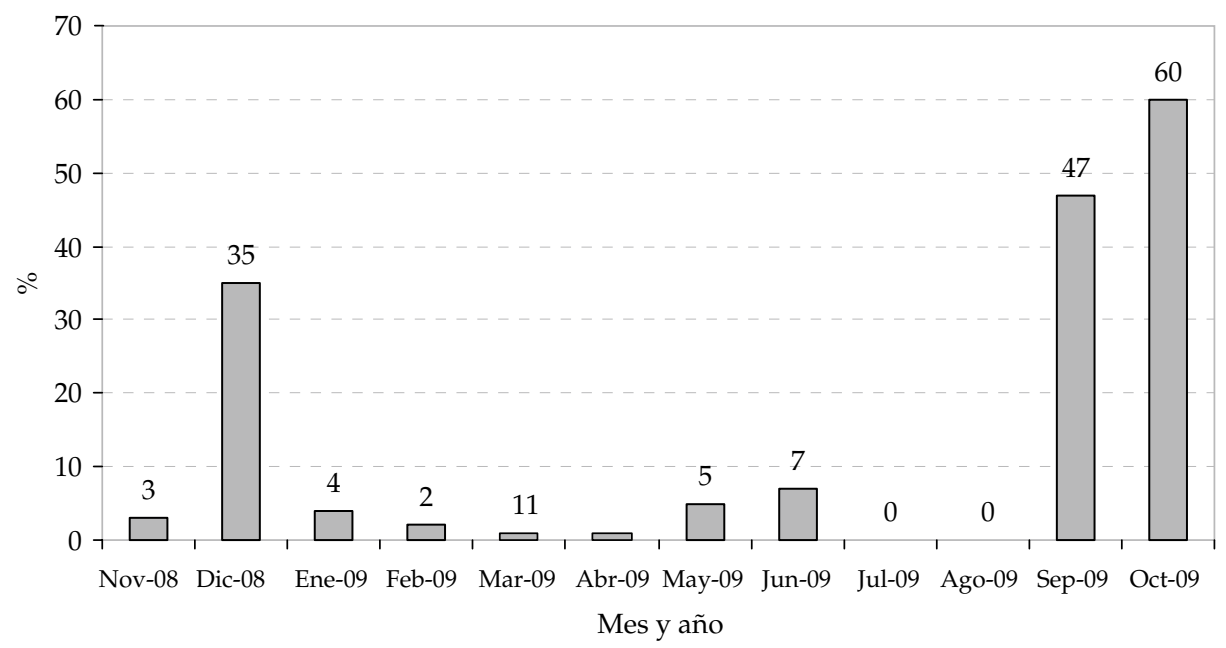

Fuente: Centro de Estudios Nueva Mayoría, http://www.nuevamayoria.com, consultado el 13-03-2010.

vez de pie, Argentina había pasado de ser el país que crecía más rápido a uno de los que evolucionaba más lentamente. El superávit fiscal se redujo, dificultando el pago de los servicios de la deuda pública. Por ello resultó necesario buscar financiamiento externo, pero los mercados privados estaban cerrados porque un porcentaje de la deuda defaulteada en 2001 no había sido renegociado y el país continuaba formalmente en cesación de pagos. Por razones de coherencia ideológica e imagen, el gobierno argentino prefirió no acudir a los organismos financieros internacionales. Venezuela, que hasta el año anterior se había tornado en prestamista de auxilio, sufría la reducción de los precios del petróleo y no estaba en condiciones de seguir otorgando créditos a tasas más bajas que el Fondo Monetario Internacional. Además, el recurso de intervenir el Instituto Nacional de Estadísticas y Censos (INDEC) para disfrazar los índices inflacionarios había mellado aún más la credibilidad del gobierno y su capacidad de recurrir a empréstitos para financiarse. Por ello, CFK anunció en diciembre la creación del "Fondo del Bicentenario" con US\$ 6.500 millones provenientes de las reservas del Banco Central (BCRA), previendo utilizarlos para pagar los servicios de la deuda. La decisión enfrentó el rechazo de la oposición y del presidente del BCRA, Martín Redrado, que objetaron la facultad presidencial de disponer de las reservas por decreto. Cuestionaban, además, la posibilidad de que el gobierno utilizase esos fondos no para pagar deuda sino para costear gastos corrientes. La puja derivó en la remoción de Redrado y la designación de Mercedes Marcó del Pont, una economista heterodoxa alineada con el oficialismo, pero la oposición consiguió abroquelarse en el Senado para resistir tanto las medidas como el nombramiento. Aunque la confirmación senatorial de Marcó del Pont finalmente se concretó por un voto, el destino de las reservas y la posibilidad de cumplir con los pagos de la deuda son inciertos. 


\section{c) Coyuntura subregional e internacional}

Durante 2009, los brasileños se cansaron de ver a su país y su presidente aparecer en las tapas de prestigiosas publicaciones mundiales: The Economist, Newsweek y The Wall Street Journal, entre otras, destacaron en diversas oportunidades y con letras de molde el nuevo milagro brasileño. Chile, por su parte, vio confirmado su ingreso como miembro pleno a la Organización para la Cooperación y el Desarrollo Económicos (OCDE), club selecto que agrupa a 28 países desarrollados y tres emergentes. Mientras Brasil y Chile fueron visitados por la mayoría de los dignatarios internacionales que recalaban en América del Sur, Argentina siguió siendo generalmente evitada como destino o escala. Aunque la comunidad diplomática internacional reconoce que ni el régimen político ni la política externa argentinos son asimilables a los de Venezuela, la imprevisibilidad del gobierno disuade a eventuales visitantes de someterse a incómodos quiebres del protocolo.

Durante la gestión de CFK las relaciones exteriores se concentraron en tres países: Venezuela, Brasil y Estados Unidos (Malamud 2010). Con Venezuela se firmaron más tratados internacionales que con las doce naciones que la siguen: el $28 \%$ del total y el $45 \%$ de los rubricados a nivel regional (López Blesué 2009; ver Gráfico 2). Con Brasil las relaciones fueron cálidas, aunque salpicadas por conflictos comerciales que el gobierno argentino no se privó de explicitar públicamente. Con Estados Unidos, a pesar de las expectativas generadas por la asunción de Barack Obama, los malentendidos y el sermoneo rutinario por parte de la Presidenta fueron una constante que se profundizó durante la crisis hondureña. Sin embargo, existió siempre un trasfondo consensual basado en dos pilares: el apoyo estadounidense a los requerimientos argentinos de financiamiento en las instituciones internacionales y la postura común, si bien por diferentes razones, frente al régimen iraní.

La integración regional continuó como presencia positiva en el discurso oficial, pero en la práctica se mantuvo congelada. A pesar de los sucesivos relanzamientos, el Mercosur redujo su peso relativo en el comercio total de sus miembros y enfrentó crecientes problemas de eficacia y legitimidad. La declamación de la voluntad política no ha impactado sobre la realidad: por ejemplo, los plazos establecidos por el Protocolo Constitutivo del Parlamento del Mercosur para adoptar un criterio de representación proporcional y convocar a elecciones directas no se han cumplido, y el tratado de creación de la Unión de Naciones Sudamericanas (UNASUR) no ha sido ratificado. No es por esa razón, sin embargo, que Uruguay vetó inicialmente la candidatura de Néstor Kirchner para presidir la organización, sino como consecuencia del conflicto bilateral sobre la administración del río homónimo. Este hecho desnuda tanto la fragilidad institucional de los procesos de integración regional como la acrimonia que envuelve a gobiernos que pertenecen, alegadamente, a la misma familia político-ideológica.

A nivel global, la crisis económica ofreció a Argentina un escenario de alto perfil: la reunión del G20 en Londres, que se realizó en abril y contó con la presencia estelar de Barack Obama. En ese encuentro de las mayores economías mundiales, que incluye también a Brasil y México y substituyó intempestivamente al G8, CFK tuvo la oportunidad de transmitir su demanda de una nueva arquitectura financiera internacional. Sin embargo, 
Gráfico 2: Países con mayor cantidad de tratados celebrados con Argentina (noviembre 2008-octubre 2009)

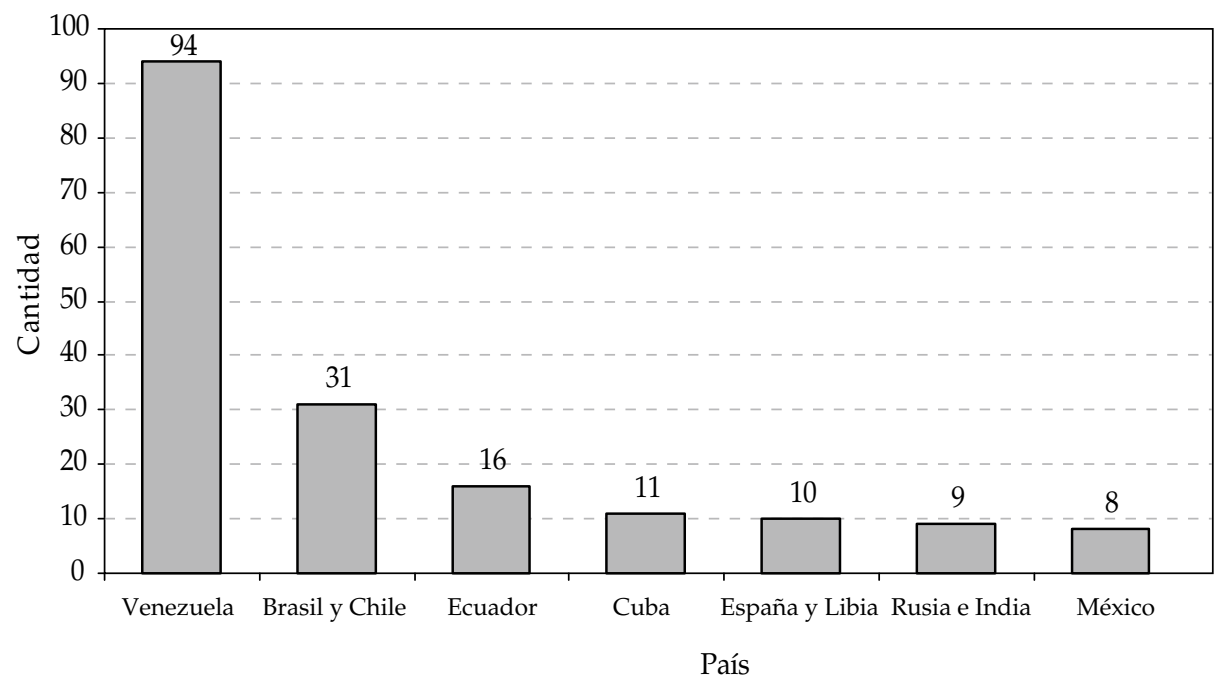

Fuente: Centro de Estudios Nueva Mayoría, http://www.nuevamayoria.com, consultado el 13-03-2010.

tanto el pico de la crisis como la espectacular irrupción del G20 resultaron efímeros, y la rápida recuperación del crecimiento económico por parte de las grandes potencias emergentes -Brasil entre ellas- contribuyó a diluir la visibilidad global de Argentina.

\section{d) Coyuntura política}

El año estuvo marcado por dos fenómenos relacionados: la primera derrota del kirchnerismo en los cuatro mayores distritos electorales y el reagrupamiento de la Unión Cívica Radical (UCR o radicales). Desde 1946 fuerza dominante en el polo no peronista, la UCR se encontraba en pronunciada dispersión desde la caída de Fernando de la Rúa en 2001. El factor aglutinante de los radicales no fue tanto la acción revulsiva del gobierno sino el fallecimiento a principios de abril de Raúl Alfonsín, primer presidente de la transición democrática y líder espiritual del partido. El velorio público y la ceremonia funeraria permitieron que los radicales de la diáspora, incluyendo a los que habían sido aliados de los K hasta el año anterior como el vicepresidente Julio Cobos, se reencontraran con quienes se habían mantenido en el partido. Ricardo Alfonsín, hijo del caudillo y candidato a diputado por PBA, cumplió un fuerte papel simbólico al marchar junto con Cobos a la cabeza de la columna mortuoria. Los radicales utilizaron con habilidad la ocasión para restañar heridas y convocar al reagrupamiento partidario, abriendo así las puertas a otra anomalía: la de un vicepresidente opositor. Desde entonces, Cobos ejerce un delicado equilibrio entre sus responsabilidades institucionales (reemplaza a la titular del Ejecutivo en caso de ausencia y preside el Senado, desempatando en caso 
de paridad) y su ostensible intención de ser el candidato de la UCR a la presidencia de la república en 2011. Las presiones del oficialismo para que renuncie al cargo no han surtido efecto, pero contribuyen a mellar su imagen positiva -la más alta entre todos los políticos argentinos. En cualquier caso, CFK enfrenta un escenario complicado: por un lado, la pérdida de la mayoría parlamentaria y de la lealtad vicepresidencial dificultan la implementación de su agenda legislativa; por el otro, la dinámica política argentina marca que el gobierno derrotado en las elecciones intermedias pierde en los comicios presidenciales posteriores. En síntesis, aunque formalmente CFK está habilitada para competir por su reelección inmediata, el escenario que se avecina presenta ribetes semejantes al síndrome del "pato rengo": un Congreso menos dócil para aprobar las iniciativas del Ejecutivo y más activo para generar las propias, y un partido de gobierno que, frente a las escasas posibilidades de éxito del incumbent, está lejos de exhibir unidad detrás de su candidatura.

\section{CAMBIOS EN LAS REGLAS DEL JUEGO POLÍTICO Y CONTINUIDAD EN LAS POLÍTICAS}

Durante 2009 el Congreso sancionó dos importantes cambios en las reglas relativas a la competencia por el poder: la modificación del calendario electoral y una nueva ley de reforma política. A su vez, en materia de políticas públicas el gobierno profundizó su preferencia por un mayor protagonismo estatal en los planos regulatorio, productivo y asistencialista.

En marzo CFK promovió una alteración en la fecha de las elecciones, por lo que los comicios de renovación legislativa fijados para el tercer domingo de octubre se adelantaban al 28 de junio (28-J). La medida, de rápida aprobación parlamentaria a pesar de las duras críticas de la oposición, buscaba dos objetivos: por un lado, frente a la incertidumbre abierta tras la crisis económica internacional y sus potenciales efectos en el plano doméstico, propiciar un escenario electoral más favorable para el gobierno; por el otro, evitar el desgaste que podría causar una progresión de resultados negativos en votaciones para cargos legislativos provinciales. ${ }^{1}$ En efecto, el anuncio de la iniciativa para alterar el almanaque electoral se hizo público tras la difusión de informes socioeconómicos sobre los primeros meses de 2009 y la sucesión, en pocos días, de dos acontecimientos adversos para el oficialismo. Primero, la derrota del PJ, unificado y con el apoyo explícito de los Kirchner, a manos de una fuerza política antes aliada al gobierno en los comicios parlamentarios de la provincia de Catamarca. Y luego, la convocatoria anticipada a elecciones legislativas en la CABA, un distrito de mayor peso y electoralmente esquivo a los K, precisamente para el 28-J.

Salvo en unas pocas provincias en donde las respectivas constituciones estipulan una fecha no congruente para elecciones provinciales y nacionales, los gobernadores poseen un amplio margen para establecer su realización en forma simultánea con las nacionales o bien para desacoplarlas o "desdoblarlas" (Oliveros y Scherlis 2004). 
Con posterioridad el gobierno impulsó un proyecto de ley de reforma política, denominada de "Democratización de la Representación Política, la Transparencia y de Equidad Electoral". La iniciativa proponía varios cambios, entre ellos 1) la realización de primarias abiertas, simultáneas y obligatorias para todos los partidos políticos, con un umbral de participación del 1,5\% del padrón de electores como requisito para presentar candidatos en la elección general, 2) la exigencia, para lograr el reconocimiento jurídico como partido político, de un número de afiliados equivalente al 4 por mil de los empadronados del distrito correspondiente, 3 ) la prohibición de financiamiento a los partidos políticos por parte de empresas u otro tipo de personas de carácter jurídico, 4) la distribución exclusiva de los espacios en radio y TV para la propaganda electoral por parte de la Dirección Nacional Electoral dependiente del Ministerio del Interior, 5) la prohibición a los partidos políticos de toda forma de contratación o adquisición de espacios de publicidad electoral radiotelevisiva.

El gobierno anticipó que la propuesta buscaba fortalecer a los partidos políticos, democratizar los procesos de selección de candidatos, promover un sistema de partidos más estructurado, terminar con la proliferación de microempresas electorales ("sellos de goma" en la jerga política vernácula) y garantizar condiciones más equitativas en la competencia por el poder. Sin embargo, distintas voces de la oposición descalificaron al paquete de reformas por considerar que favorecía a los tradicionales PJ y UCR, perjudicaban a las organizaciones políticas minoritarias y obstaculizaban la consolidación de nuevas agrupaciones partidarias de destacable desempeño en la votación del 28-J. En efecto, entre los potenciales afectados por el cambio de reglas podría señalarse, ante todo, a las fuerzas encabezadas por Francisco de Narváez, empresario de meteórica carrera política forjada a base de abundantes spots televisivos adquiridos con ingentes fondos privados, y por Fernando "Pino" Solanas, responsable de un inesperado segundo lugar en CABA y carente de una organización con un mínimo de afiliados.

A pesar del rechazo de los principales bloques parlamentarios opositores y de no contar, como en otros proyectos, con el apoyo de los legisladores de centroizquierda, el gobierno reunió trabajosa y ajustadamente el sostén de la mayoría absoluta de los miembros de cada Cámara, asegurándose así cumplir con el requisito fijado por la Constitución nacional para la sanción de leyes modificatorias del régimen electoral y de partidos políticos. ${ }^{2}$

Entre las distintas iniciativas legislativas promovidas por CFK y aprobadas por el Congreso con posterioridad al 28-J sobresalió, por su nivel de controversia e impacto, la propuesta sobre "Servicios de Comunicación Audiovisual" o más sencillamente "Ley de Medios". El proyecto oficialista anunciaba como objetivos principales actualizar la regulación existente en el área, propiciar una mayor injerencia estatal en el control del cumplimiento de la normativa vigente, desconcentrar el mercado de radiodifusión, facilitar la entrada de nuevos actores como los medios comunitarios y las asociaciones sin fines de lucro, y promover la producción sobre temas nacionales, provinciales y locales mediante los "cupos

2 Sin embargo, hacia fines de mayo de 2010 existe incertidumbre sobre la vigencia de los cambios, pues la ley aún no ha sido reglamentada por el Poder Ejecutivo. 
de contenido". El impulso gubernamental a la medida profundizó el enfrentamiento entre los $\mathrm{K}$ y las empresas del sector ubicadas en una posición dominante, como las del descollante Grupo Clarín y el matutino porteño La Nación. ${ }^{3}$

Mientras que por cuestiones de orientación ideológica el diario La Nación había mantenido una postura crítica hacia los K casi desde la misma asunción de Néstor Kirchner en 2003, la confrontación entre el gobierno y el Grupo Clarín estalló en 2008 durante el conflicto por las "retenciones" agropecuarias. A partir de entonces, las declaraciones de distintos funcionarios gubernamentales cuestionando las posturas del multimedio fueron más frecuentes y feroces, a la vez que la línea editorial de Clarín endurecía sus críticas hacia la gestión. La pugna entró en una nueva fase cuando en agosto de 2009 la Asociación de Fútbol Argentino (AFA) rescindió su contrato de televisación por 268 millones de pesos con la empresa TyC Sports (propiedad del Grupo Clarín) y el gobierno adquirió los derechos en 600 millones, estipulando como principales condiciones la transmisión de todos los partidos en directo y la asignación del excedente de ganancia por comercialización a la promoción del deporte amateur. La refriega se trasladó también a los tribunales, donde varios fallos judiciales han dejado en suspenso la aplicación de la "Ley de Medios".

\section{ELECCIONES: EQUILIBRIO ENTRE POLOS Y RECONFIGURACIÓN INTRA POLOS}

Las elecciones nacionales incluyeron la renovación de un tercio de las bancas del Senado (24 sobre 72) y de la mitad de la Cámara de Diputados (127 de un total de 257 escaños). Los comicios senatoriales se desarrollaron en ocho provincias mediante un sistema de lista incompleta: dos bancas asignadas al partido con más votos y una para el segundo, independientemente de la cantidad de sufragios obtenidos por ambos o de la distancia entre ellos. Las votaciones para diputados nacionales, en cambio, tuvieron lugar en las veinticuatro (24) provincias del país, en distritos electorales plurinominales de magnitud variable: dos distritos grandes (PBA con 35 y CABA con 13 cargos en juego), cuatro medianos (Córdoba y Santa Fe con 9 bancas cada uno, y Mendoza y Entre Ríos, ambos con 5), y dieciocho pequeños (con 4 o menos cargos). Al igual que los senadores, los diputados fueron elegidos en listas partidarias cerradas y bloqueadas, mientras que los escaños se adjudicaron por fórmula proporcional D'Hondt y umbral legal del tres por ciento del padrón electoral. Simultáneamente a la renovación legislativa nacional, nueve (9) provincias votaron para cargos legislativos distritales y, de éstas, ocho (8) también lo hicieron para órganos representativos municipales.

El adelantamiento del calendario electoral obligó a los partidos políticos a decidir sus candidaturas en un plazo menor al habitual. Esta circunstancia contribuyó a que el proceso de selección de candidatos se dirimiera vía acuerdos de cúpula antes que

El grupo Clarín es propietario del diario homónimo (el de mayor difusión), de Canal Trece (el segundo canal de TV abierta), de Radio Mitre y de la principal proveedora de TV por cable, además de un número importante de empresas editoriales, productoras de contenidos audiovisuales, proveedoras de conexión a Internet e imprentas gráficas. Por su parte, el diario La Nación, de tendencia conservadora, es el segundo en tirada. 
mediante votaciones primarias, mecanismo utilizado en forma frecuente por los partidos mayoritarios en contiendas previas, aunque en declive desde fines de la década del 90 (De Luca, Jones y Tula, 2002, 2009). A su vez, el oficialismo desplegó una estrategia conocida como "candidaturas testimoniales": postular a funcionarios públicos de alto rango, con el objetivo de convertir a la elección legislativa en un plebiscito sobre las políticas promovidas por CFK. Más allá de procurar la alineación del electorado, la maniobra apuntaba a la organización partidaria peronista, en cuyas filas se pretendía, sobre todo, evitar defecciones electoralmente costosas. Aunque alentada para un alcance nacional, en los hechos esta estrategia se limitó casi en forma exclusiva al crucial distrito de la PBA. En ésta, el candidato a diputado nacional Néstor Kirchner fue secundado por el gobernador Daniel Scioli y el jefe de gabinete de ministros de la nación Sergio Massa, mientras que medio centenar de funcionarios e intendentes encabezaron las nóminas de postulantes a legisladores provinciales o a los concejos municipales. ${ }^{4}$

Por otra parte, y como consecuencia del enfrentamiento entre el gobierno y los productores rurales por las "retenciones", las organizaciones de este sector (principalmente la FAA, Federación Agraria Argentina, las CRA, Confederaciones Rurales Argentinas, y la SRA, Sociedad Rural Argentina) promovieron la postulación de sus dirigentes en diferentes listas opositoras, dando lugar al fenómeno de los "agrocandidatos".

Como en anteriores ocasiones, el oficialismo o "peronismo K" se presentó bajo la etiqueta del "Frente para la Victoria" (FPV) agrupando a aliados menores. En esta oportunidad, sin embargo, ciertos líderes peronistas provinciales se distanciaron de los Kirchner y en sus distritos presentaron listas de candidatos diferentes a la patrocinada oficialmente por el FPV; tal fue el caso del senador nacional Carlos Reutemann (Santa Fe) y del gobernador Juan Schiaretti (Córdoba). Otros dirigentes de extracción peronista, en cambio, se alinearon claramente en oposición a los K y apoyaron a "Unión-PRO", la asociación constituida por Mauricio Macri (jefe de gobierno de CABA y líder de la centroderechista PRO, Propuesta Republicana), Francisco de Narváez (empresario y diputado nacional por PBA) y Felipe Solá (peronista disidente, ex gobernador de PBA). Autoconcebido más como "movimiento" que como "partido", la competencia entre dos o más listas de cuño peronista frente al electorado general ya registraba antecedentes, como por ejemplo el enfrentamiento entre "ortodoxos" y "renovadores" en la década de 1980, la presentación de tres candidatos presidenciales en 2003 o la división entre "kirchneristas" y "duhaldistas" en 2005 (Malamud 2008).

$4 \quad$ En el proceso de selección de candidatos, las autoridades partidarias nacionales fijan las reglas y, entre otros aspectos, la política de alianzas del partido en todo el país. Empero, las ramas provinciales de la organización gozan de un amplio margen de autonomía para tomar las decisiones que atañen a su distrito. Por ello, por ejemplo, dos partidos políticos pueden conformar una coalición electoral en una o más provincias, pero no necesariamente ese acuerdo se establece en las veinticuatro (e inclusive, en uno o más distritos pueden presentarse en coaliciones enfrentadas).

5 Para un panorama sobre el conflicto entre el gobierno y los ruralistas, véase Leiras y Cruzalegui (2009). Un reflejo del fenómeno de los "agrocandidatos" en los artículos “Agrodiputados" (La Nación, 23/05/2009), “La cosecha de los agrodiputados" (Página 12, 30/06/2009) y “Los agrodiputados van divididos al Congreso" (Crítica, 30/11/2009) 
Por su parte, la UCR, la Coalición Cívica (CC) de Elisa "Lilita" Carrió y el Partido Socialista (PS) conformaron el "Acuerdo Cívico y Social" (ACyS), un frente que presentó una lista de candidatos común en dieciséis (16) de los veinticuatro (24) distritos. El ACyS aglutinó también a dirigentes y grupos del denominado "pan-radicalismo", un heterogéneo grupo conformado tanto por aquellos que habían abandonado a la UCR tras la crisis del 2001 como por los que, sin separarse de ésta, habían apoyado a los Kirchner tanto en el plano gubernamental como en el electoral (i.e. los denominados "radicales K").

Los resultados de las elecciones no arrojaron un claro ganador a nivel nacional. Los candidatos de "Unión-PRO" triunfaron en las estratégicas CABA y PBA, pero este notable desempeño no se repitió en ninguna otra provincia, desnudando las limitaciones territoriales de este conglomerado político. El ACyS logró importantes victorias en cinco distritos, y la conquista de una significativa cantidad de escaños la convirtió en el segundo bloque en importancia en ambas cámaras legislativas. ${ }^{6}$ Sin embargo, esta coalición arribó en tercer lugar tanto en PBA como en CABA y segundo en Santa Fe. Por su parte, el FPV obtuvo un total de 42 bancas de diputados que le permitieron mantener su condición de primera minoría, pero sufrió la pérdida de 18 de los 60 cargos que ponía en juego y cayó derrotado en los cuatro principales distritos del país que, sumados, equivalen al 52 por ciento de los escaños en disputa y al 70 por ciento del electorado.

En el recuento provincia por provincia, el resultado más resonante fue el obtenido por "Proyecto Sur", una lista de centro-izquierda encabezada por el director de cine y ex diputado Fernando "Pino" Solanas. Carente de organización política y con escasos recursos, alcanzó el segundo lugar en CABA con el 24,2\% de los sufragios. A nivel nacional el FPV obtuvo poco más del 31,2 por ciento de los votos, el ACyS el 30,7\%, Unión-PRO más los peronistas disidentes el 18,7\%, el PJ no kirchnerista el $8 \%$ y el centroizquierda el 1,7\% (ver Cuadro 1).

Para sintetizar el escenario tras las elecciones legislativas resulta útil apelar a la clásica división de la política argentina de los últimos sesenta años en dos polos, uno peronista y uno no peronista. Los votos de 2009 promovieron un equilibrio entre polos y, al mismo tiempo, una reconfiguración intra polos: en el primero, de primacía kirchnerista a reparto por tercios entre peronistas K, no K y anti K; en el segundo, de fragmentación y dispersión crecientes a concentración y recuperación de la UCR.

Entre los "agrocandidatos" ingresó como senadora la liberal y miembro de SRA Josefina Meabe de Mathó, mientras que once fueron electos diputados nacionales, de los cuales siete por la UCR -como Pablo Orsolini (vicepresidente $1^{\circ}$ de FAA), Ulises Forte (vicepresidente $2^{\circ}$ de FAA) y Ricardo Buryaile (vicepresidente $2^{\circ}$ de CRA). Al conquistar tal representación legislativa los ruralistas se convirtieron en un fenómeno político novedoso: desde 1983, el ámbito parlamentario nacional había registrado la presencia de un único grupo sectorial

6 El aumento de la representación parlamentaria del ACyS fue, sin embargo, dispar: la UCR sumó 15 nuevos miembros en la Cámara de Diputados y la CC sólo uno, mientras que el PS perdió cuatro. 
Cuadro 1: Elecciones 2009. Resultados para diputados nacionales

\begin{tabular}{lcr}
\hline \multicolumn{1}{c}{ Partido político o coalición } & Votos & $\%$ \\
\hline Frente para la Victoria (FPV) & 5.871 .345 & 31,2 \\
Acuerdo Cívico y Social (ACyS) y otros & 5.763 .342 & 30,7 \\
Propuesta Republicana (PRO) y PJ disidente & 3.519 .843 & 18,7 \\
PJ no kirchnerista & 1.518 .572 & 8,0 \\
Centroizquierda & 982.533 & 5,2 \\
Izquierda & 317.306 & 1,7 \\
Otros & 832.323 & 4,5 \\
Total & 18.805 .264 & \\
\hline
\end{tabular}

Fuente: Clarín, 30/06/2009.

definido, los "dipusindicales"- es decir, los legisladores de extracción gremial, identificados mayoritariamente con el peronismo.?

En cuanto a la representación femenina, los resultados determinaron un 38,5\% de legisladoras en la Cámara de Diputados y un 35,2\% en el Senado. Con este registro, Argentina ocupa el primer lugar entre las democracias latinoamericanas. ${ }^{8}$ Esta posición es consistente con los antecedentes del país en la materia: los argentinos han sido pioneros en la adopción de una estricta ley nacional de cupo femenino, que comenzó a aplicarse en 1993 para la conformación de la Cámara de Diputados y en 2001 para el Senado.

La ronda electoral de 2009 culminó en octubre con la desfasada votación para gobernador en la provincia de Corrientes, en donde un particular duelo entre primos registró un desenlace inusual: el incumbent Arturo Colombi apoyado por los K fue derrotado por el radical y opositor Ricardo Colombi. ${ }^{9}$

\section{LA PRESIDENCIA: LIDERAZGO CONCENTRADO Y DE CONFRONTACIÓN}

Desde su asunción, CFK mantuvo un estilo de gestión presidencial muy similar al de su antecesor y esposo Néstor Kirchner: fuerte concentración de la toma de decisiones en el vértice del Poder Ejecutivo, inexistencia de reuniones de gabinete, escasa predisposición a

7 Sobre los "dipusindicales", véase los artículos "Los diputados de la discordia" (Clarín, 21/06/1991), "Cede en Diputados el poder sindical" (La Nación, 16/05/1993), "Resurge el bloque sindical-peronista" (La Nación, 15/11/1999), “Una representación cada vez más debilitada en el Congreso” (La Nación, 21/01/2000), “Más legisladores de extracción sindical" (Clarín, 16/10/2001).

8 Datos extraídos de http://www.ipu.org/wmn-e/classif.htm el 10 de marzo de 2010.

9 En la Argentina post-1983, la probabilidad de victoria de un gobernador (electo popularmente) que compite por su reelección es de 8,5 sobre 10 (cálculo a partir de datos de los autores). 
las conferencias de prensa (y preferencia por los discursos por cadena nacional) y ejercicio de un liderazgo de confrontación. La oposición en general y Julio Cobos en particular, el Grupo Clarín, el sector agropecuario y, en menor medida, los jueces se mantuvieron entre los blancos más usuales en los discursos de la presidenta y de los funcionarios ministeriales, recibiendo respectivamente los calificativos de "golpistas", "monopólicos", "destituyentes" y "partido judicial". Frente al Congreso, el gobierno mantuvo su apego a la regla de la mayoría y, después del 28-J, impulsó el rápido tratamiento de varios proyectos clave, anticipando que vetaría toda iniciativa que pretendiera derogarlos o modificarlos después del recambio parlamentario.

Luego de la derrota electoral fueron reemplazados los ministros a cargo de la jefatura de gabinete y de Economía. Estas dos carteras, usualmente las más importantes junto con la de Interior, han registrado el mayor número de cambios de titulares desde la asunción de CFK: tres ministros cada uno (ver Cuadro 2). Por el contrario, otros funcionarios polémicos, como el secretario de Comercio Interior, Guillermo Moreno, fueron ratificados en sus cargos. Poco después de presentar su renuncia como presidente del PJ, Néstor Kirchner decidió retornar al puesto para garantizar el sostén partidario al gobierno.

Cuadro 2: Gabinete CFK 2007-2009*

\begin{tabular}{cccc}
\hline Cartera ministerial & Diciembre de 2007 & Enero de 2009 & Diciembre de 2009 \\
\hline Jefafura de Gabinete de Ministros & Alberto Fernández & Sergio Massa & Aníbal Fernández \\
Interior & Florencio Randazzo & Florencio Randazzo & Florencio Randazzo \\
Economía & Martín Losteau & Carlos Fernández & Amado Boudou \\
Relaciones Exteriores, Comercio Internacional y Culto & Jorge Taiana & Jorge Taiana & Jorge Taiana \\
Defensa & Nilda Garré & Nilda Garré & Nilda Garré \\
Planificación Federal, Inversión Pública y Servicios & Julio De Vido & Julio De Vido & Julio De Vido \\
Justicia, Seguridad y Derechos Humanos & Aníbal Fernández & Aníbal Fernández & Julio Alak \\
Educación & Juan Carlos Tedesco & Juan Carlos Tedesco & Alberto Sileoni \\
Ciencia, Tecnología e Innovación Productiva & Lino Barañao & Lino Barañao & Lino Barañao \\
Trabajo, Empleo y Seguridad Social & Carlos Tomada & Carlos Tomada & Carlos Tomada \\
Salud & Graciela Ocaña & Graciela Ocaña & Juan Luis Manzur \\
Desarrollo Social & Alicia Kirchner & Alicia Kirchner & Alicia Kirchner \\
Industria y Turismo & $* *$ & Débora Georgi & Débora Georgi \\
Agricultura, Ganadería y Pesca & $* * *$ & & Julián Domínguez \\
\hline
\end{tabular}

Notas:

* Todos los ministros son designados y despedidos exclusivamente por el Presidente de la República, a excepción del Jefe de Gabinete de Ministros, que también puede ser removido por una mayoría de ambas cámaras del Congreso.

** Ministerio creado en noviembre de 2008.

*** Ministerio creado en septiembre de 2009.

Diciembre 2007: En cursivas, los ministros que venían desempeñándose en el cargo desde la presidencia de Néstor Kirchner.

Fuente: Elaboración propia sobre diarios nacionales. 


\section{CONGRESO: SESIONES Y LEYES AL RITMO DEL CALENDARIO ELECTORAL}

La actividad del Congreso en 2009 estuvo marcada por el modificado calendario electoral. En los recintos de ambas cámaras se desarrollaron intensos debates sobre temas de relevancia, pero el ritmo de la labor parlamentaria se acopló a los vaivenes de la coyuntura del 28-J. Desde la apertura de las sesiones ordinarias en marzo y hasta fines de junio, los diputados se reunieron en sesión plenaria sólo tres veces y los senadores cuatro: la ley más importante tratada en esta fase fue el proyecto de adelantamiento de los comicios legislativos.

Tras las elecciones, en cambio, el trabajo se incrementó: en la Cámara de Diputados las sesiones fueron once ( 15 menos que el período legislativo anterior) y en el Senado 13 (con otras tantas menos que el año previo). En minoría a partir de diciembre, el gobierno aprovechó su situación mayoritaria hasta el 10 de diciembre para lograr la aprobación de un conjunto de iniciativas consideradas clave. Así logró la sanción de la prórroga de las facultades delegadas al Ejecutivo, la "Ley de Medios", la prórroga de los impuestos a las ganancias y al cheque, el presupuesto para 2010, la eliminación de los delitos de calumnias e injurias, la obtención compulsiva de sangre para examen de $\mathrm{ADN}$, la reapertura del canje de la deuda, la prórroga de la emergencia económica y la reforma política. Las votaciones favorables hacia estos proyectos se forjaron sobre un sólido bloque oficialista, al que se sumaron en forma habitual varios grupos de centroizquierda considerados como aliados y una coalición ad hoc de legisladores individuales. Así y todo, varias de estas iniciativas se sancionaron con un apoyo mayoritario estricto (Cuadro 3).

Cuadro 3: Principales votaciones legislativas en el Congreso (2009)

\begin{tabular}{|c|c|c|c|c|c|c|c|c|}
\hline \multirow[b]{2}{*}{ Ley - denominación } & \multirow[b]{2}{*}{$\begin{array}{c}\text { Ley - } \\
\text { número }\end{array}$} & \multicolumn{3}{|c|}{ Cámara de Diputados } & \multicolumn{3}{|c|}{ Senado } & \multirow[b]{2}{*}{$\begin{array}{l}\text { Fecha de } \\
\text { sanción }\end{array}$} \\
\hline & & $\begin{array}{c}\text { A } \\
\text { favor }\end{array}$ & $\begin{array}{c}\text { En } \\
\text { contra }\end{array}$ & Abstención & $\begin{array}{c}\text { A } \\
\text { favor }\end{array}$ & $\begin{array}{c}\text { En } \\
\text { contra }\end{array}$ & Abstención & \\
\hline Adelantamiento elecciones* & 26.495 & 136 & 109 & 8 & 42 & 26 & 0 & 26 de marzo \\
\hline Prórroga facultades delegadas al Ejecutivo & 26.519 & 136 & 100 & 7 & 38 & 30 & 0 & 20 de agosto \\
\hline de Medios & 26.522 & 147 & 4 & 1 & 44 & 24 & 0 & 10 de octubre \\
\hline Prórroga impuestos ganancias y cheque & 26.545 & 137 & 97 & 0 & 41 & 26 & 0 & 12 de noviembre \\
\hline Presupuesto 2010 & 26.546 & 136 & 88 & 6 & 42 & 25 & 0 & 12 de noviembre \\
\hline Reapertura canje de la deuda & 26.547 & 165 & 28 & 5 & 45 & 10 & 0 & 18 de noviembre \\
\hline Extracción compulsiva de ADN & 26.549 & 154 & 32 & 14 & 57 & 1 & 0 & 18 de noviembre \\
\hline Eliminación delitos calumnias e injurias & 26.551 & 152 & 13 & 5 & 52 & 0 & 0 & 18 de noviembre \\
\hline Prórroga de la emergencia económica & 26.563 & 131 & 52 & 3 & 35 & 28 & 0 & 25 de noviembre \\
\hline Reforma política* & 26.571 & 133 & 99 & 4 & 42 & 24 & 0 & 2 de diciembre \\
\hline
\end{tabular}

* Exigían requisito de mayoría absoluta en cada Cámara.

Fuentes: Dirección de Información Parlamentaria, HCDN y diarios nacionales. 
Gráfico 3: Leyes según poder de iniciativa y año de sanción (1983-2009)

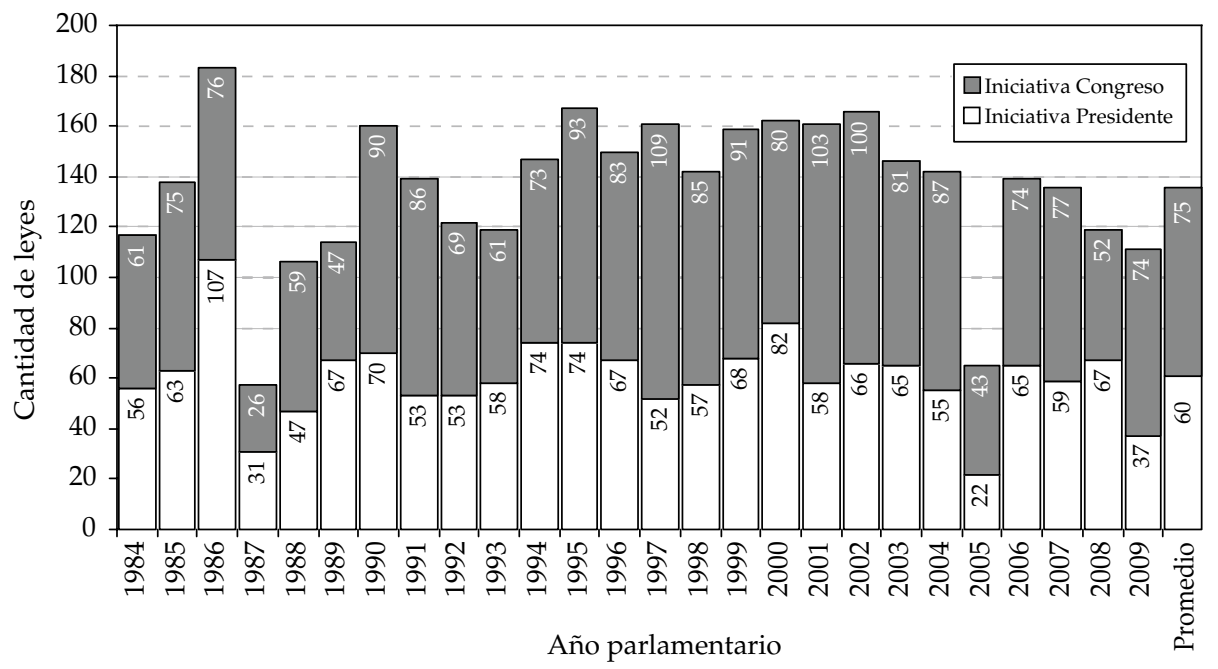

Nota: En 1983 el Congreso comenzó a funcionar en diciembre. En ese año parlamentario se sancionaron 21 leyes, todas iniciadas por la Presidencia.

Fuente: Dirección de Información Parlamentaria, HCDN.

La reactivación de las tareas parlamentarias tras el 28-J permitió redondear en el período una producción parlamentaria cercana al promedio: 111 leyes sancionadas contra una media de 114 para los años 1984-2009. Otro dato para destacar es el bajo porcentaje de leyes sancionadas por iniciativa del Ejecutivo: apenas un tercio, uno de los registros más bajos para el mismo período (Gráfico 3).

Las cámaras experimentaron asimismo una extensión del transfuguismo parlamentario. Fenómeno en crecimiento tras la crisis de 2001, desde la asunción de Néstor Kirchner en 2003 éste estuvo orientado casi exclusivamente hacia el gobierno, promotor y beneficiario de las defecciones en los bloques legislativos opositores. Desde fines de 2008, en cambio, el transfuguismo se ha registrado también -y en modo ascendente- desde el gobierno hacia la oposición.

\section{TENSAS RELACIONES ENTRE CONGRESO, PRESIDENCIA Y JUSTICIA}

Antes del 28-J la oposición y los principales medios de comunicación solían referirse al Congreso como una "escribanía" de la presidencia y a la mayoría de los jueces como subordinados a los designios oficialistas. Incluso organismos como el Consejo de la Magistratura eran considerados dependientes de la voluntad de los Kirchner. A partir de diciembre, sin embargo, el recambio legislativo confirmó que aquel diagnóstico, ya cuestionado por sucesos como el rechazo al aumento de las retenciones agropecuarias en el Senado, era errado. Independientemente de la evaluación sobre la gestión de CFK, 
la vigencia del régimen democrático no está en cuestión: las iniciativas presidenciales pierden votaciones en el Congreso y la Justicia dictamina con frecuencia en contra de medidas del gobierno.

El primer conflicto institucional derivado de la nueva relación de fuerzas parlamentarias se expresó en la designación de las autoridades de ambas Cámaras. La oposición, alegando que el oficialismo había quedado en minoría, se unió para reclamar la mayoría de los representantes en todas las comisiones legislativas y la presidencia de al menos la mitad de ellas, además de las vicepresidencias del Senado y la Cámara de Diputados. Aunque algunos líderes opositores manifestaron su intención de disputar las presidencias de ambas Cámaras, la UCR no acompañó la demanda. Sin embargo, el conflicto abierto entre las cabezas del Ejecutivo (la presidenta) y el Legislativo (el vicepresidente de la República y presidente del Senado, Julio Cobos) se mantuvo caldeado, llegando la Presidenta a suspender un viaje al exterior para evitar que Cobos la substituyera. Más aún, en los meses subsiguientes las disputas entre el Ejecutivo y el Legislativo tendieron a transformarse en conflictos de poderes, dando lugar a un proceso de judicialización de la política por medio del cual la Presidenta y el Congreso pretenden imponer su posición en los estrados judiciales. En cuestión, más que elementos substantivos como la posibilidad de pagar deuda pública con reservas monetarias, está la competencia del Ejecutivo para tomar ese tipo de decisiones mediante decretos "de necesidad y urgencia" o la del Congreso para determinar medidas administrativas. En cuanto al Poder Judicial, aunque la independencia de algunos jueces no era tan evidente antes de la derrota electoral del oficialismo, la imparcialidad de la Corte Suprema nunca estuvo en duda, a pesar de que el propio Néstor Kirchner había designado a buena parte de sus integrantes, o precisamente por el hecho de haber nombrado a profesionales fuera de sospecha. Actualmente algunos miembros prominentes del gobierno están siendo investigados por corrupción, lo que hasta el momento produjo la renuncia del secretario de Transporte, Ricardo Jaime, y de tres secretarios privados de CFK. Asimismo, la Justicia ha promovido indagaciones en negocios administrados por sindicatos oficialistas, llegando incluso a encarcelar al notorio dirigente gremial y aliado kirchnerista Juan José Zanola.

\section{FEDERALISMO ESTILO ARGENTINO: ENTRE LA AFINIDAD PARTIDARIA Y LA DEPENDENCIA FINANCIERA}

Al igual que otros países que combinan presidencialismo y federalismo, la dinámica política argentina integra las relaciones entre los poderes y procesos de gobierno en sus dimensiones horizontal y vertical. Mientras en 2009 los vínculos entre Ejecutivo, Legislativo y Judicial ingresaron en una fase de tensión creciente, la interacción entre el gobierno nacional y los provinciales siguió el patrón clásico del federalismo argentino post-1983: un doble juego entre afinidad partidaria y dependencia financiera. En los albores de su presidencia, la combinación de altos índices de popularidad, anuncios de obras públicas y cuantiosas partidas presupuestarias permitió a Néstor Kirchner un fácil alineamiento de los ejecutivos provinciales, incluso de aquellos no peronistas (i.e. "los radicales K"). El conflicto con el sector rural, el descenso de CFK en las encuestas y la derrota del 28-J erosionaron progresivamente el apoyo de los gobernadores hacia 
la administración nacional. Sin embargo, la dependencia financiera de las provincias y la discrecionalidad presidencial en el manejo de los recursos coparticipables no sólo evitaron desacoples mayores entre los gobernadores del PJ (dos tercios del total), sino que mantuvieron a raya a los de otros partidos.

Un patrón similar se ha registrado en el plano municipal, ya que partidos no peronistas gobiernan la mayoría de las principales ciudades del Interior (Córdoba, Rosario, Mendoza, Santa Fe) y los Kirchner mantienen el apoyo entre la mayoría de los intendentes justicialistas del conurbano, la veintena de comunas que rodea la CABA y en donde vive casi una cuarta parte de los argentinos.

\section{UNA DEMOCRACIA DE BAJA CALIDAD}

$\mathrm{Si}$, como afirmara Adam Przeworski, la democracia se define como el sistema en el que los partidos pierden elecciones, la derrota del gobierno en las urnas en 2009 ratificaría la efectiva existencia de un régimen de este tipo en Argentina. Sin embargo, la presencia de elecciones competitivas encubre la ausencia relativa del segundo elemento de la definición: los partidos. Como muchos politólogos saben por sufrimiento propio, en Argentina es prácticamente imposible llegar a un acuerdo respecto al número efectivo de partidos electorales o parlamentarios, y más aún usar un índice de nacionalización partidaria. Tampoco es fácil analizar la composición del gabinete o de la coalición gobernante en términos partidarios, ya que hay peronistas en la oposición y miembros de otras fuerzas políticas, principalmente radicales, en el gobierno. La responsabilización (accountability) de los representantes es un criterio básico de calidad democrática, por lo que la fluidez partidaria, al dificultar la identificación colectiva de los dirigentes, exhibe uno de los aspectos degradados de la política argentina posterior al colapso de 2001. Sin embargo, la percepción de los actores es menos problemática que la de los observadores. Aunque la legislación electoral federal permite que los partidos nacionales se presenten en cada provincia con diferentes alianzas y bajo distintos rótulos, tanto los líderes como buena parte del electorado son capaces de distinguir "parecidos de familia" y agrupar a los dirigentes políticos en unos pocos grupos significativos, los más destacados de los cuales son hoy el kirchnerismo, el peronismo no kirchnerista y el panradicalismo. Según los estudios de opinión pública, de estos sectores provienen los candidatos con más probabilidad de ganar las elecciones presidenciales de 2011. Esos mismos estudios detectan la baja popularidad del gobierno (CFK ronda persistentemente el $30 \%$ de imagen positiva) y una insatisfacción generalizada contra la dirigencia, pero al mismo tiempo ratifican que el apoyo hacia la democracia sigue siendo mayoritario.

Recientemente Guillermo O'Donnell (2010) ha vuelto a alertar sobre el riesgo de "deslizamiento" hacia el autoritarismo que la crisis de las llamadas "democracias delegativas" podría generar. Siendo estas últimas una subespecie de la democracia menos virtuosa que su contraparte representativa, la alarma de O'Donnell indica que la continua pérdida de calidad puede derivar en la desnaturalización, o aún quiebra, del régimen. Al presente no se visualiza un menoscabo de la democracia en Argentina: existen controles verticales efectivos (los gobiernos pierden elecciones y aceptan el resultado) y controles horizontales operativos (una prensa libre y generalmente 
opositora, mayorías legislativas que derrotan iniciativas presidenciales, jueces que dictaminan en contra del Ejecutivo). Al mismo tiempo, se comprueba una marcada insatisfacción popular (sobre todo con las autoridades pero también con la oposición) y un desempeño gubernamental mediocre (tanto en la calidad como en los resultados de las políticas públicas). En síntesis, la democracia argentina no aparece frágil, pero su rendimiento es defectuoso. El problema no residiría en el vínculo representativo, que se ha mantenido más firme de lo que muchos temieron desde 2001, sino en su capacidad de ofrecer resultados y satisfacer expectativas. El déficit, en síntesis, es del Estado antes que del régimen político.

\section{REFERENCIAS}

De Luca, Miguel, Mark P. Jones y María Inés Tula. 2002. “Back Rooms or Ballot Boxes? Candidate Nomination in Argentina", Comparative Political Studies 35(4), 413-36.

De Luca, Miguel, Mark P. Jones y María Inés Tula. 2009. “Revisando las consecuencias políticas de las primarias. Un estudio sobre las elecciones de gobernador en la Argentina", POSTData $13,81-102$.

Ichaso, Josefina. 2009. "Los piqueteros realizaron el $60 \%$ de los cortes de ruta y vías públicas de octubre”, Informe Centro de Estudios Nueva Mayoría, 3 de noviembre.

Leiras, Marcelo e Inés Cruzalegui. 2009. "Argentina: problemas macroeconómicos, conflicto social y debilitamiento de la coalición de gobierno", Revista de Ciencia Política, 29 (2), 223-45.

López Blesué, Milagros. 2009. “Los Kirchner continúan eligiendo a Venezuela a la hora de firmar tratados bilaterales", Informe Centro de Estudios Nueva Mayoría, 18 de diciembre.

Malamud, Andrés. 2008. "¿Por qué los partidos argentinos sobreviven a sus catástrofes?", Iberoamericana. América Latina-España-Portugal [Berlín] 8(32), 158-65.

Malamud, Andrés. 2011. "Argentine Foreign Policy under the Kirchners: Ideological, Pragmatic or just Peronist?", en Latin American Foreign Policies between Ideology and Pragmatism, editado por Gian Luca Gardini y Peter Lambert. Palgrave, en prensa.

O'Donnell, Guillermo. 2010. "El riesgo de un deslizamiento de la democracia al autoritarismo", Clarín, $12 / 01 / 2010$.

Oliveros, Virginia y Gerardo Scherlis. 2004. “¿Elecciones concurrentes o elecciones desdobladas? La manipulación de los calendarios electorales en la Argentina, 1983-2003", en ¿Qué cambió en la política argentina?, editado por Isidoro Cheresky y Jean-Michel Blanquer. Rosario: Homo Sapiens, 179-211.

\section{Fuentes de información}

Organismos públicos: Dirección de Información Parlamentaria, Honorable Cámara de Diputados de la Nación. Dirección Nacional Electoral, Ministerio del Interior.

Diarios nacionales: Clarín, La Nación, Perfil, Página 12, Crítica.

Otros: Centro de Estudios Nueva Mayoría.

Miguel De Luca es Doctor en Ciencia Política por la Universidad de Florencia (Italia). Profesor en la Universidad de Buenos Aires e investigador del CONICET. Los temas de su especialidad son las instituciones políticas y los procesos de gobierno, los partidos políticos y los sistemas electorales [E-mail: migueldeluca@yahoo.com].

Andrés Malamud es investigador adjunto en el Instituto de Ciencias Sociales de la Universidad de Lisboa. Doctorado en Ciencia Política por el Instituto Universitario Europeo (Florencia), sus áreas de interés incluyen integración regional comparada, instituciones de gobierno, política latinoamericana y migraciones transatlánticas [E-mail: andres.malamud@eui.eu]. 
